\title{
26 Research Square \\ Early Biomarkers Associated with P53 Signaling for Acute Radiation Injury
}

\section{Weihong Li}

South China Agricultural University College of Forestry

\section{Shixiang Zhou}

Beijing Institute of Radiation Medicine

\section{Meng Jia}

Beijing Institute of Radiation Medicine

\section{Xiaoxin Li}

Beijing Institute of Radiation Medicine

\section{Lin Li}

Beijing Institute of Radiation Medicine

\section{Qi Wang}

Beijing Institute of Radiation Medicine

\section{Zhenhua Qi}

Beijing Institute of Radiation Medicine

\section{Pingkun Zhou}

Beijing Institute of Radiation Medicine

\section{Yaqiong Li}

Beijing Institute of Radiation Medicine

Zhidong Wang ( $\sim$ wangzhidong_1977@aliyun.com )

Beijing Institute of Radiation Medicine https://orcid.org/0000-0003-0594-1638

\section{Research}

Keywords: Radiation accident, P53, Radiation injury biomarker

Posted Date: November 10th, 2021

DOI: https://doi.org/10.21203/rs.3.rs-1039179/v1

License: (9) This work is licensed under a Creative Commons Attribution 4.0 International License. Read Full License 
Version of Record: A version of this preprint was published at Life on January 11th, 2022. See the published version at https://doi.org/10.3390/life12010099. 


\section{Abstract}

Background: Rapid and accurate high-throughput estimation of radiation dose aims to help medical rescue in nuclear radiation accident. However, current methods of dose estimation are still lacking of speedy or accuracy. P53 signaling pathway plays an important role in DNA damage repair and cell apoptosis induced by ionizing radiation. The changes of radiation-induced P53 related genes in the early stage of ionizing radiation should compensate for the deficiency of lymphocyte decline and $\mathrm{y}-\mathrm{H} 2 \mathrm{AX}$ analysis as novel biomarkers of radiation damage.

Methods: Bioinformatic analysis was performed on previous data to find candidate genes from human peripheral blood irradiated in vitro. The radiation sensitivity and baseline levels of candidate genes were verified. The approximate threshold for guiding medical treatment was estimated for each gene, and four genes were combined to construct an effectively early dose estimation model of radiation.

Results: Four p53-related genes, DDB2, AEN, TRIAP1 and TRAF4, were screened and verified their significant radiosensitivity. Their expressions were stable without gender or age difference in healthy population, but significantly up-regulated by radiation, with time specificity and dose dependence in $2 \mathrm{~h}$ $24 \mathrm{~h}$ after irradiation. Further studies showed these genes can be used as indicators for early medical treatment in acute radiation injury. The effective combination of the four genes could achieve a more accurate dose assessment and injury classification for large-scale wounded patients within 24 hours post exposure.

Conclusions: This is the first time to investigate the potential biomarkers of ionizing radiation by systematic study. The effective combination of the four genes provides a new model for dose estimation and injury classification of a large number of exposed population in acute nuclear accidents, and also provides a new idea and method.

\section{Introduction}

Timely estimation of radiation dose and classification of damage for large numbers of wounded, in the early stage of nuclear accidents, will effectively guide the application of treatment plans and improve the capacity of treatment and rescue.

The $0.5 \mathrm{~Gy}$ irradiation will cause a slight decline of peripheral blood lymphocytes counts and recover spontaneously. A total of $2 \mathrm{~Gy}$ irradiation can cause obvious decline of peripheral blood lymphocyte counts and inhibition of hematopoietic function, which usually requires medical treatment. However, $6 \mathrm{~Gy}$ and above irradiation can significantly inhibit hematopoietic function, which requires hematopoietic factor application or hematopoietic stem cell transplantation. Therefore, it is essential to classify the wounded accurately and rapidly for deciding the treatment of the wounded. Nuclear radiation accidents usually happen accidentally, and the exposed individual will not carry physical dosimeters. Thus, biological dose estimation technology is crucial for the classification and dose assessment of wounded after nuclear accidents. Currently, applied biological dose estimation methods mainly include lymphocyte 
chromosome aberration analysis, lymphocyte count analysis and lymphocyte $\mathrm{Y}-\mathrm{H} 2 \mathrm{AX}$ analysis and so on (1-5). Among them, lymphocyte chromosome aberration analysis is considered as the "gold standard" for biological dose estimation of radiation for its higher specificity and accuracy. However, high requirements for operators are needed, including more than $48 \mathrm{~h}$ cell culture before specimen preparation and analysis. Furthermore, the upper limit of dose detection is 5-6Gy (6). lonizing radiation causes a significant decline in peripheral blood lymphocytes, and the degree was dramatically related to the dose. The lymphocyte count analysis within 12 to 48 hours after irradiation was used for classification and preliminary dose estimation of patients with radiation injury. However, there are large differences between individuals, resulting in low accuracy $(7,8)$. Since $y-H 2 A X$ is recognized as a key biomarker of doublestrand break (DSB) and has great specificity to ionizing radiation. The $\mathrm{Y}-\mathrm{H} 2 \mathrm{AX}$ Foci analysis is widely used for identifying ionizing radiation. But the window period of $\mathrm{Y}-\mathrm{H} 2 \mathrm{AX}$ foci change is short. It appears several minutes after irradiated, the peak comes at $1 \mathrm{~h}$ and starts to decrease. Moreover, the operation is complicated and cannot achieve high-throughput detection, which limit its widely application $(9,10)$. In addition, peripheral blood lymphocyte count analysis can be used for triage in large number of patients, and the accurate dose can only be estimated by chromosome aberration analysis. According to the technical characteristics of both methods, it is impossible to apply lymphocyte count analysis earlier than 12 hours after irradiation, either achieve patient classification and dose assessment by the early postaccident period chromosome aberration analysis.

Deoxyribonucleic acid (DNA) damage and apoptosis are the most basic and critical aspects of the biological effects of radiation and can be used as markers of ionizing radiation (11-14). Cells will immediately initiate apoptosis, once DNA damage repair fails $(15,16)$. 0.5-1Gy irradiation can induce DNA damage and apoptosis for peripheral blood lymphocytes which are very sensitive to irradiation (17, 18). P53 signaling pathway plays an extremely important role in both DNA damage repair and the initiation of apoptosis (14). Specifically, DNA double strand breaks (DSBs) induced by radiation activate ataxia telangiectasia mutation (ATM) $(19,20)$, which phosphorylate and activate checkpoint kinase Chk2 (21). Consequently, P53 is activated and the stability of P53 is enhanced, which result in cell cycle arrest at G1/S phase and provide a critical opportunity for cells to restore genomic integrity prior to DNA replication. Repairable DNA damage tends to be transient, whereas sustained P53 activation will induce the cells to initiate apoptotic program $(17,22)$. P53 signal plays an important regulatory role in the whole process of ionizing radiation-induced DNA damage and lymphocyte apoptosis. Enhanced P53 activity is a key marker for DNA damage and cell cycle arrest. Thus, the significant changes of radiation-induced P53 signaling related genes in the early stage of ionizing radiation should be served as novel biomarkers of radiation damage, which may compensate for the deficiency of lymphocyte decline and $\mathrm{y}-\mathrm{H} 2 \mathrm{AX}$ analysis.

In our previous study, a variety of radiation sensitive genes were found in human peripheral blood after $2 \mathrm{~h}$ irradiation (23). We then further investigate the early sensitive genes which were mainly related to the P53 signaling pathway. Four genes (DDB2, AEN, TRIAP1 and TRAF4) were identified and stable real-time quantitative fluorescence PCR detection methods were established respectively, to verify their radiation sensitivity and baseline levels in healthy population. Our results showed that the levels of 4 genes in 
peripheral blood were dose and time dependent significantly at different time and dose range within $24 \mathrm{~h}$ after exposure. Further studies indicated that the baseline levels of the four genes in healthy population could not be affected by gender and age. Taken together, we assessed rough thresholds for each gene at different detection time points as guidelines for medical treatment and combined four genes according to their different change patterns in the early radiation stage. We aim to build an effective early radiation dose estimation model, which assist to injury triage and dose estimation of large quantities of people exposed to nuclear radiation.

\section{Materials And Methods}

\section{Human Peripheral Blood Sample Collection}

Peripheral blood samples were collected from 32 healthy volunteers aged between 20 to 50 years (female: 15, male: 17). None of them had a history of smoking, drinking, acute or chronic diseases, and no X-ray has been exposed. Blood samples were collected intravenously with anticoagulant EDTA-K2.

\section{Radiation and culture in vitro}

The whole human peripheral blood sample was incubated in a water bath at $37^{\circ} \mathrm{C}$ to simulate the in-vivo environment, and divided into 7 groups and irradiated in 0Gy, 0.5Gy, 1Gy, 2Gy, 4Gy, 6Gy and 10Gy respectively with ${ }^{60} \mathrm{Co}-\gamma$ radiation at a dose rate of $1.14 \mathrm{~Gy} / \mathrm{min}$. The samples were cultured at a constant temperature in an incubator at $37^{\circ} \mathrm{C}$ after irradiation, and collected at $0 \mathrm{~h}, 2 \mathrm{~h}, 4 \mathrm{~h}, 8 \mathrm{~h}, 12 \mathrm{~h}$ and $24 \mathrm{~h}$ after irradiation. Total Ribonucleic Acid(RNA) was extracted for subsequent detection.

\section{RNA extraction and QRT-PCR}

Primer pairs and probes for each gene were designed and synthesized by Gemma Company (Shanghai) according to the genetic information retrieved from GenBank. The specific sequence and amplification product size are detailed in (Supplementary table3).

Concentration and purity of RNA was extracted from blood samples using RNAprep Pure Blood Kit (QIAGEN, Hilden, Germany) were quantitated by NanoDrop 2000 (Thermo Fisher Scientific, Rockford, IL), and the integrity was detected by $1.5 \%$ agarose gel electrophoresis. The PrimeScriptTM RT Reagent Kit with gDNA Eraser was used to reverse transcriptional complementary DNA (CDNA) as a template.

According to the genetic information retrieved from GenBank, the primers and probes of each gene were designed and synthesized by Gemma Company, Shanghai. ITaq ${ }^{\mathrm{TM}}$ Universal SYBR Green Supermix (BIORAD) was used for QRT-PCR analysis through TaqMan probe two-step Real Time PCR. The relative levels of candidate gene expression were calculated using the formula $2-\triangle \Delta C T$ as described in user manual.

\section{Plasmid construction and standard curve drawing}

Total RNA was extracted from the collected peripheral blood samples and reverse-transcribed into cDNA using PRIME Scripttm RT Reagent Kit with GDNA Eraser Kit. The target gene fragments of TRAF4, DDB2, 
AEN, TRIAP1 and $\beta$-actin were amplified using reverse transcribed cDNA as the template, and then linked to $\mathrm{PMD}-18 \mathrm{~T}$ vector and confirmed by sequencing. The plasmid concentration measured by spectrophotometer was converted into molar concentration. The genes $\beta$-actin, TRAF4, DDB2, POLH, GADD45A and TNFSF9 were amplified by MYIQTM2 real-time quantitative PCR using plasmid standards of different concentrations as templates. The mole number of the standard plasmid was transformed into the copy number of the plasmid according to the formula Copies $/ \mu \mathrm{l}=\left(6.02 \times 10^{23}\right) \times(\mathrm{ng} /$ $\left.\mu \mathrm{l} \times 10^{-9}\right) /($ DNA Length $\times 660$ ) and then logarithm transformed as the abscissa of the curve. The ordinate of the curve is the Cycle threshold (CT) values at different concentrations measured experimentally. The standard curves of $\beta$-actin, TRAF4, DDB2, GADD45A and TNFSF9 genes were plotted according to the above methods. The equation of the standard curve is $y=-a x+b$.

\section{Statistical analysis}

The results of the experiment used the relative quantitative analysis method of $2^{-\Delta \Delta C T}$. $\beta$-actin was used as the reference gene to measure the messenger RNA (mRNA) expression level of radiation-sensitive genes. PCR data analysis and comparison between groups were performed by SPSS18.0 (IBM). Bilateral One-way analysis of variance test were used, with $P<0.05$ as significant difference. The dose-time response relationships of individual radiation-responsive genes were analyzed by linear or nonlinear regression methods. (Partial least-regression)PLS regression analysis was used to establish a dosimetry model of gene expression. $\mathrm{R}^{2}$ values were used to determine the goodness of fit for all models.

\section{Result}

\section{lonizing radiation induced the expression of P53 signaling related genes including DDB2, AEN, TRIAP1 and TRAF4}

We conducted an in-depth analysis of NimbleGen genome-wide chip data from the peripheral blood samples of 3 healthy adults with doses of $0 \mathrm{~Gy}, 0.75 \mathrm{~Gy}, 2 \mathrm{~Gy}$ and $6 \mathrm{~Gy}$ at $2 \mathrm{~h}$ after irradiation. For each dose group, we screened genes with expression fold change greater than 2 times in the three samples as differentially expressed genes (Figure1a and Supplementary table1). 4 genes, including AEN, BBC3, TRAF4 and TRIAP1, were significantly increased in all three samples after $0.75 \mathrm{~Gy}$ radiation. Meanwhile, all of them were shown significant difference in 2Gy and 6Gy dose groups. The number of differentially expressed genes were 37 and 36 in 2Gy and 6Gy groups, in which 19 genes were same. Subsequently, functional annotation analysis was conducted for the differential expressed genes of each dose group. The results showed that the differentially expressed genes in $0.75 \mathrm{~Gy}$ and other dose groups were enriched into few signal pathways. The most significant pathway enriched was P53 downstream pathway, as well as TP53 regulates transcription of cell death genes and TP53 regulates transcription of DNA repair genes. These results indicated that P53-related signaling pathways significantly changed in peripheral blood after irradiation (Figure1a).

We then compared all differentially expressed genes enriched in TP53-related signaling pathways in different databases and our results revealed a total of 17 differentially expressed genes were involved in 
TP53-related signaling pathways (Supplementary table2). We then explored the levels of the 17 differentially expressed genes, and screened 7 genes with stable expressions in the three samples in 0Gy group, but increase or decrease in at least two dose groups (Figure 1b). Among them, 3 differentially expressed genes POLH, RPS27L and GADD45A have been proved to be closely related to dose of radiation and have been reported as radiation biomarkers (24-28). Previous studies have shown that DDB2 was a radiative biomarker. However, most of them were focused on sequencing and screening and lack of detailed studies on time-dose effect (29). Therefore, our study steps to the other four differentially expressed genes, DDB2, AEN, TRIAP1 and TRAF4 and explore their feasibility as biomarkers for early response to ionizing radiation damage.

\section{Establishment of real time PCR detection method for DDB2, AEN, TRIAP1 and TRAF4 genes}

We used peripheral blood cDNA as a template to optimize the amplification temperature conditions for primers of DDB2, AEN, TRIAP1, TRAF4 and internal reference gene $\beta$-actin. Real Time PCR was performed at the annealing temperatures of $58,59,60,61$ and $62^{\circ} \mathrm{C}$. The results showed that there was no significant difference in the CT values of all genes within this temperature range (Figure 2a). Finally, we chose $60^{\circ} \mathrm{C}$ as the optimal annealing temperature for all 5 genes, after comprehensive comparison and analysis. Then, we constructed pMD18T- $\beta$-actin, pMD18T-DDB2, pMD18T-AEN, pMD18T-TRIAP1 and PMD18T-TRAF4 plasmids respectively, and the standard plasmid was diluted to a concentration of $6 \times 10^{8}$ copies by a 10 -fold gradient. The minimum concentration was $6 \times 10^{2}$ copy numbers and real-time quantitative PCR was performed. As shown in Figure.2b, we obtained uniform amplification curves with a CT interval of about 3.33, and all had strong fluorescence for all above 5 plasmids. Subsequently, the standard curve was shown in Figure.2.c, with the logarithmic copy number of plasmid standard as the abscissa $X$ and the $C T$ value as the ordinate $Y$. The results showed that there was an obvious linear relationship between the plasmid copy numbers and CT values, and the fitting equations were as follows: $\beta$-Actin $Y=-3.31 X+42.72$, DDB2 $Y=-3.40 X+37.04$, AEN $Y=-3.54 X+40.92$, TRIAP1 $Y=-3.63 X+40.57$, TRAF4 $Y=-3.71 X+40.96$. All correlation coefficients $R^{2}$ were greater than 0.99 and less than 1 , respectively: $\beta$ Actin $\mathrm{R}^{2}=0.994$, DDB2 $\mathrm{R}^{2}=0.992$, AEN R$^{2}=0.996$, TRIAP1 $\mathrm{R}^{2}=0.995$, TRAF4 $\mathrm{R}^{2}=0.997$.

\section{Time and dose effect analysis of ionizing radiation induced gene expressions}

In order to analyze the time and dose effects of the four candidate genes after irradiation, human venous blood was irradiated with 0-10Gy $\mathrm{Y}$-rays in vitro, and samples were collected at $0 \mathrm{~h}, 2 \mathrm{~h}, 4 \mathrm{~h}, 8 \mathrm{~h}, 12 \mathrm{~h}$ and 24h after irradiation. The expression of DDB2 gene showed a significant dose-dependently increase at four time points from $4 \mathrm{~h}$ to $24 \mathrm{~h}$ after irradiation, and peaked at $8 \mathrm{~h}$ after irradiation. At $24 \mathrm{~h}$ after irradiation, the expression of DDB2 was still significantly higher in the 0.5Gy irradiation groups than nonirradiated group (Figure.3a). The expression of AEN gene showed a significant increase dosedependently at all four time points from 2 to $12 \mathrm{~h}$ after exposure, and began to increase after $2 \mathrm{~h}$ exposure, peaked at $8 \mathrm{~h}$ to $12 \mathrm{~h}$ after exposure, and then fell from $24 \mathrm{~h}$ exposure. However, it was still higher than that of the unexposed group (Figure.2a). The expression of TRIAP1 gene was significantly up-regulated from $2 \mathrm{~h}-24 \mathrm{~h}$ after irradiation, and peaked at $8 \mathrm{~h}$ after irradiation. At $2 \mathrm{~h}$ and $4 \mathrm{~h}$ after irradiation, the expression 
level of TRIAP1 increased significantly in different dose groups, but there was no significant dosedependent relationship. At 8h, 12 and 24h after irradiation, the expression level of TRIAP1 at each dose point was significantly higher than that in the unirradiated group, showing a dose-dependent increase (figure.2a, middle and bottom). The increase of TRAF4 gene expression mainly occurred at 2-8h after irradiation, and there was no significant change at 12 and 24 hours after irradiation. At $2 \mathrm{~h}$ after radiation, the expression level of TRAF4 was mainly up-regulated in the 6Gy and 10Gy groups, while the expression level of TRAF4 gene showed an increasing trend after 4Gy and below irradiation, but there was no statistical significance. At $4 \mathrm{~h}$ after exposure, the expression level of TRAF4 reached a peak and increased dose-dependently, then began to fall back at $8 \mathrm{~h}$ after exposed and fell back to the normal level at $24 \mathrm{~h}$ after exposure (Figure.2a bottom).

Comprehensive analysis showed that, those four genes had characteristic patterns in the time range and dose range of early radiation response. As shown in Figure 2b, DDB2 had significant time and dose effects after 4 to 8 h post irradiation. AEN showed a significant dose effect from 2 to 8 h post-exposure. The TRIAP1 pair dose was significant from $8 \mathrm{~h}$ to $24 \mathrm{~h}$ post-exposure. The detection window period for TRAF4 was shorter, at 4 to $8 \mathrm{~h}$ after irradiation.

\section{Expressions of DDB2, AEN, TRIAP1 and TRAF4 in healthy population}

To further evaluate the feasibility of DDB2, AEN, TRIAP1, and TRAF4 as biomarkers of radiation injury, we collected venous blood from 29 healthy volunteers (age ranging from 20 to 50 years old, male: 15 and female: 14) to conduct a preliminary analysis of the expression levels of these four genes in healthy population. The results showed that the distribution of baseline levels of four genes in healthy population was uniform and stable, without large fluctuations (Figure.4a). The average copy number of DDB2, AEN, TRIAP1 and TRAF4 genes in 29 healthy people were DDB2: $0.204 \pm 0.049$, AEN: $0.056 \pm 0.010$, TRIAP1: $0.170 \pm 0.031$, TRAF4: $0.0924 \pm 0.031$ respectively; and the fluctuation range were DDB2: $0.103 \sim 0.326$, AEN: 0.041-0.075, TRIAP1: 0.101-0.248, TRAF4: 0.023 0.146 respectively. Further analysis showed that there was no significant difference of these four genes between male and female. The levels in male and female groups were DDB2: $0.208 \pm 0.053,0.200 \pm 0.047, P=0.695$; AEN: $0.055 \pm 0.011,0.057 \pm 0.010, P=0.278$; TRIAP1: $0.174 \pm 0.033,0.166 \pm 0.029 ; P=0.445$; TRAF4: $0.091 \pm 0.035,0.094 \pm 0.028, P=0.787$ (figure.4b). Finally, 29 samples were divided into 3 groups according to age. We aim to investigate whether the genes expressions were affected by age, including 10 people aged 21 to 30 years, 10 people aged 31 to 40 years and 9 people aged 41 to 50 years. The expression levels of DDB2 in all age groups were $0.219 \pm 0.062$, $0.199 \pm 0.034$ and $0.194 \pm 0.049(P>0.05)$, and there was no significant difference among all groups. The expression levels of AEN in different age groups were $0.066 \pm 0.007,0.051 \pm 0.008$ and $0.052 \pm 0.008$. There was no significant difference in pairwise comparison among all groups $(P>0.05)$. The expression levels of TRIAP1 gene in all age groups were $0.179 \pm 0.033,0.170 \pm 0.031$ and $0.160 \pm 0.029(P>0.05$, Figure.4c). The expression levels of TRAF4 gene in 3 groups were $0.107 \pm 0.032,0.071 \pm 0.027$ and $0.100 \pm 0.022$. The $P$ values comparison between the 31-40 years group and the other two groups were 0.017 and 0.021 (Figure.4c bottom). 
DDB2, AEN, TRIAP1 and TRAF4 can be used as indicators for early medical treatment in acute radiation injury

For the stability of the expression levels of four genes in healthy population, we plotted the population normal distribution curve and estimated the $95 \%$ confidence interval based on central limit theorem. The results are shown in Figure 5a and Table1. Their central values, standard deviations and 95\% confidence intervals in the normal distribution model are DDB2:Mean $=0.196, S T D=0.038$, $\mathrm{Cl}=0.120 \sim 0.271$;AEN:Mean=0.051, STD=0.014, $\mathrm{Cl}=0.023-0.079$; TRIAP1:Mean=0.176, STD=0.040, $\mathrm{Cl}=0.096 \sim 0.256$; TRAF4:Mean $=0.092, \mathrm{STD}=0.031, \mathrm{Cl}=0.030 \sim 0.154$. The coefficient of variation and the fold change of the maximum and minimum values within the confidence interval were respectively $\mathrm{DDB} 2: \mathrm{CV}=0.194, \mathrm{FC}_{\mathrm{bg}}=2.264 ; \mathrm{AEN}: \mathrm{CV}=0.275, \mathrm{FC}_{\mathrm{bg}}=3.435 ; \mathrm{TRIAP1}: \mathrm{CV}=0.228, \mathrm{FC}_{\mathrm{bg}}=2.677$;

TRAF4:CV=0.336, $\mathrm{FC}_{\mathrm{bg}}=5.106$. Once the fold changes of the above genes before and after exposure beyond the multiple of $\mathrm{FC}_{\mathrm{bg}}$ or the copy number of expressed exceeds the $95 \%$ confidence interval in human peripheral blood changes, which may indicate that the individual maybe exposed to ionizing radiation.

Table 1

Model of estimation for Threshold of exposure to ionizing radiation

\begin{tabular}{|llllll|}
\hline Item Gene & $\boldsymbol{\mu}$ & $\boldsymbol{\sigma}$ & $\mathbf{C V}$ & $\mathbf{9 5 \%} \mathrm{Cl}$ & FC(bg) \\
\hline DDB2 & 0.196 & 0.038 & 0.194 & $0.120 \sim 0.271$ & 2.264 \\
\hline AEN & 0.051 & 0.014 & 0.275 & $0.023-0.079$ & 3.435 \\
\hline TRIAP1 & 0.176 & 0.040 & 0.228 & $0.096 \sim 0.256$ & 2.677 \\
\hline TRAF4 & 0.092 & 0.031 & 0.336 & $0.030 \sim 0.154$ & 5.106 \\
\hline $\begin{array}{l}\text { H: mean; } \sigma: \text { standard deviation; CV: Coefficient of Variation; Cl: confidence interval; FC(bg): The } \\
\text { maximum of fold change in background. }\end{array}$ & & & \\
\hline
\end{tabular}

Since 2Gy whole-body irradiation is usually required for medical treatment, we then further compared the $\mathrm{FC}_{\mathrm{bg}}$ of DDB2, AEN, TRIAP1 and TRAF4 expression and the ratio of maximum to minimum value within the confidence interval of baseline level at different time points after irradiation in healthy population. In combination with the data in Figure 3b, we aim to find early indicators for medical treatment in exposed patients. The minimum values of fold changes were chosen among groups radiated more than $2 \mathrm{~Gy}$ in each time point compared with the FC (bg), and the larger one was selected as FC value. We can identify the individual who have been exposed in radiation at more than 2Gy when the up-regulation of gene expression exceeds the corresponding FC, and then medical treatment is needed. Correspondingly, we took the product of $\mathrm{FC}$ and $\boldsymbol{\mu}$, the central value of population normal distribution curve, as the approximate threshold for considering medical treatment. For example, the change of AEN expression level is the main factor in $2 \mathrm{~h}$ after irradiation. Once the fold change of AEN expression exceeds 3.44 or the copy number exceeds $0.051 * 3.44=0.18$, it can be confirmed that the individual was irradiated with more than 2Gy. In 4h after irradiation, the DDB2 expression increased multiple was more than 2.26 or the 
expressed copy number exceeds $0.196 * 2.26=0.44$; the AEN expression increased multiple was more than 7.01 or the expressed copy number exceeds $0.051 * 7.01=0.36$; the expression of TRIAP 1 increased multiple of 3.65 or the copy number of expression exceeded $0.176 * 3.65=0.64$, and the TRF 4 expression increased multiple of 5.63 or the copy number of expression exceeded $0.092 * 5.63=0.52$; each of them could be regarded as the threshold for medical treatment when the exposure dose exceeded $2 \mathrm{~Gy}$. In the case of sufficient medical resources, if the expression level of more than one of the four genes reaches the threshold, attention should be paid and immediate medical treatment should be given. Their respective threshold values could also be recognized at 8-24h after irradiation (Table 2). Medical treatment must be considered if there are more than two time points within 2-24h after exposure, at which the dosage reach the indications for medical treatment.

Table 2

Model of estimation for Threshold of medical treatment

\begin{tabular}{|c|c|c|c|c|c|c|c|c|c|c|}
\hline \multirow[t]{2}{*}{ Item Gene } & \multicolumn{2}{|l|}{$2 \mathrm{~h}$} & \multicolumn{2}{|l|}{$4 h$} & \multicolumn{2}{|l|}{$8 h$} & \multicolumn{2}{|l|}{$12 \mathrm{~h}$} & \multicolumn{2}{|l|}{$24 h$} \\
\hline & FC & Copies & FC & Copies & FC & Copies & FC & Copies & FC & Copies \\
\hline DDB2 & - & - & 2.26 & 0.44 & 8.16 & 1.6 & 5.37 & 1.05 & 7.1 & 1.39 \\
\hline AEN & 3.44 & 0.18 & 7.01 & 0.36 & 10.7 & 0.54 & 6.52 & 0.33 & - & - \\
\hline TRIAP1 & - & - & 3.65 & 0.64 & 5.92 & 1.04 & 5.12 & 0.90 & 3.69 & 0.84 \\
\hline TRAF4 & - & - & 5.63 & 0.52 & - & - & - & - & - & - \\
\hline
\end{tabular}

Based on existing experience, radiation of $6 \mathrm{~Gy}$ or above can cause significant inhibition in hematopoietic function, which requires the application of hematopoietic factors or hematopoietic stem cell transplantation, earlier treatment, the better curative effect. Thus, we decided to screen for indications that can guide transplantation in the early post irradiation. The minimum of the fold change of expression in 6Gy and above groups were selected as the value of FC at each detection time point, where the expression level of the target gene in 6Gy and above was significantly higher than that in the 4Gy and below groups and greater than that in $\mathrm{FC}(\mathrm{BG})$. These indicate that radiation dosage of patient who has exceeded 6 Gy could be identified when the fold change was greater than FC.

We also used the product of $\mathrm{FC}$ and $\mu$, the central value of population normal distribution curve, as the approximate threshold for hematopoietic factor application and hematopoietic stem cell transplantation must be performed. Details are shown in Table 3. Early transplant therapy must be considered if there are more than two time points within $2-24 \mathrm{~h}$ after exposure at which the dosage reach the indications. 
Table 3

Model of estimation for Threshold of transplantation therapy

\begin{tabular}{|llllllllllll|}
\hline Item Gene & $\mathbf{2 h}$ & & $\mathbf{4 h}$ & \multicolumn{3}{c}{$\mathbf{8 h}$} & \multicolumn{3}{c|}{$\mathbf{1 2 h}$} & \multicolumn{3}{c|}{$\mathbf{2 4 h}$} \\
\cline { 2 - 12 } & FC & Copies & FC & Copies & FC & Copies & FC & Copies & FC & Copies \\
\hline DDB2 & - & - & 2.97 & 0.58 & 12.4 & 2.42 & 9.09 & 1.78 & 7.99 & 1.56 \\
\hline AEN & 4.86 & 0.25 & 9.29 & 0.47 & - & - & 12.5 & 0.64 & - & - \\
\hline TRIAP1 & - & - & - & - & 9.35 & 1.64 & 6.32 & 1.11 & 4.85 & 0.85 \\
\hline TRAF4 & - & - & 7.33 & 0.68 & - & - & - & - & - & - \\
\hline FC: fold change; Copies: the number of copies of the target gene per 100 copies of $\beta$-actin. \\
\hline
\end{tabular}

\section{Combination of DDB2, AEN, TRIAP1 and TRAF4 can be used for acute radiation injury prediction}

Since DDB2, AEN, TRIAP1 and TRAF4 had significant differences in time window of response to ionizing radiation, the combination of them could perfectly cover all the time periods within a day after exposure (Figure.5b).Therefore, the combination of them at different time periods after radiation were explored for the prediction according to the unique variation patterns. We aim to build a dose assessment model with good accuracy for the exposed dose above $0.5 \mathrm{~Gy}$ at any time period within $24 \mathrm{~h}$ after radiation. Firstly, the dose estimation equation for each gene was fitted at different time points in time window. The results are shown in Figure 5c: Equations for AEN were Dose2h=1.5129*AEN-1.8314, $R^{2}=0.9946$;

Dose4h=0.0935e $\mathrm{e}^{0.4508^{\star} A E N}, R^{2}=0.9083$; Dose8 $h=0.1685 \mathrm{e}^{0.2132^{\star} A E N}, R^{2}=0.9737$. Equations for DDB2 were Dose4h=4.6682 $* D D B 2-7.4239, \mathrm{R}^{2}=0.9697$; Dose8h=0.6926*DDB2-3.1684, $\mathrm{R}^{2}=0.9755$;

Dose12h $=0.2054 \mathrm{e} 0.3563^{*} \mathrm{DDB} 2, \mathrm{R}^{2}=0.9542$. Equations for TRIAP1 were: Dose $\mathrm{h}=0.1956 \mathrm{e}^{0.3743^{*} \mathrm{TRIAP} 1}$, $\mathrm{R}^{2}=0.995$; Dose12h=0.1147e $\mathrm{e}^{0.6063^{*} \mathrm{TRIAP} 1}, \mathrm{R}^{2}=0.9743$; Dose24h=0.5452*TRIAP12-1.6696*TRIAP1+1.2567, $R^{2}=0.9899$. Equations for TRAF4 were: Dose $4 h=0.158 e^{0.4637^{*} \text { TRAF } 4}, R^{2}=0.9814$; Dose $=0.0912 e^{1.026^{*} \text { TRAF4 }}$, $\mathrm{R}^{2}=0.9804$. Then we took the fitting formula of each gene as the new independent variables DDB2', AEN', TRIAP1'and TRAF4' at $4 \mathrm{~h}-12 \mathrm{~h}$ after irradiation to fit the final dose estimation equations through PLS fitting algorithm. The results are shown in Figure 5c: Dose4h $=0.374 *$ TRAF4'+0.541 * DDB2', $\mathrm{R}^{2}=0$; Dose8h $=0.111 * A E N^{\prime}-0.109 *$ TRIAP1'+0.941 * DDB2'+0.080 * TRAF4', $\mathrm{R}^{2}=0.881 ;$ Dose12 $\mathrm{h}=0.616$ * TRIAP1'+ 0.412 * DDB2', $\mathrm{R}^{2}=0.867$.

\section{Discussion}

Current methods of dose estimation are still lacking of speedy and accuracy, in the face of a large number of casualties caused by nuclear or radiation accidents. Therefore, it is urgent to discover new radiation biodosimeter and radiation dose assessment model. They will guide medical personnel to classify injuries and develop effective treatment plans quickly in the early stage of accidents to minimize casualties. 
In our previous study, a variety of radiation sensitive genes were found $2 \mathrm{~h}$ after irradiation from human peripheral blood irradiated in vitro (23). The present study found four sensitive genes DDB2, AEN, TRIAP1 and TRAF4 from the gene chip data. Further biological analysis indicated that they are closely related to P53 signal and could be used as biomarkers of acute irradiation. It has been reported that DDB2 (Damage-specific DNA-binding protein 2) encodes DNA damage-binding protein 2, which is recognized as a radiation sensitive gene (30-32). DDB2 is increased and activated after the body exposing to ionizing radiation, then binds to DNA damage sites and induces the up-regulation of P53 expression level, which eventually participates in the nucleotide excision repair pathway (NER) (33-35). As a radiation sensitive gene, AEN is a downstream gene in P53 regulatory network pathway and could promote apoptosis (36, 37). TRIAP1, also known as P53CSV, is an apoptosis suppressor gene, which may bind P53 gene coding sequence (38). It is a target gene directly regulated by P53 during DNA damage, cell apoptosis and cell cycle inhibition. In certain stress, P53 regulates TRIAP1 transcription and DNA damage induces endogenous levels of TRIAP1(39). TRIAP1 prevents the mitochondrial pathway of apoptosis, and loss of TRIAP1 affects the accumulation of cardiolipin, which is prone to apoptosis, under internal or external stimuli(37).TRAF4, a member of the TNF receptor-related factor family, encodes a 54kD connexin consisted of 470 amino acid, is highly expressed in a variety of cancer cells $(40,41)$.TRAF4 has been widely recognized as a common target of the P53 family in previous studies $(42,43)$ due to the presence of binding site approximately $1 \mathrm{~KB}$ upstream of the promoter (44). It has been reported that Mir-29 promotes apoptosis in a P53-dependent manner through TRAF4/AKT/MDM2 pathway in glioma (45). It is also revealed that TRAF4 interacts with the deubiquitinating enzymes USP10, blocks the binding of P53 to USP10 and induce P53 instability (46). In summary, DNA damage-induced gene DDB2 is significantly up-regulated in the early stage of ionizing radiation, which induces P53 signal activation, and drives the biological processes, such as P53-mediated cell cycle arrest, DNA damage repair and cell apoptosis. As the most significant and direct biological effect of ionizing radiation, the four radiation sensitive genes are closely related to this process.

Rapid reduction of lymphocyte count is one of the main clinical manifestations of acute external irradiation injury. However, the onset time and degree of lymphocytopenia after exposure are related to dose and individual sensitivity. The number of peripheral blood lymphocytes decreased is significantly $12 \mathrm{~h}$ after irradiation when irradiation dose is exceeded $0.5 \mathrm{~Gy}$. The degree of reduction was positively correlated with the dose in the range of $0.5 \sim 10 \mathrm{~Gy}$ (47). At present, exposure dose is mainly estimated based on the absolute value of lymphocytes $12 \mathrm{~h}$ or $24-48 \mathrm{~h}$ after irradiation, and the applicable is limited to $10 \mathrm{~Gy}$. Moreover, since the absolute value of lymphocytes in healthy population is closely related to age, sex, race and other factors, the single analysis of absolute value of lymphocytes has certain inaccuracy. Therefore, the dynamics of absolute changes of lymphocytes should be adopted for analysis. However, samples should be collected at least 2 hours apart. In our study, the expression levels of DDB2, AEN, TRIAP1, and TRAF4 were significantly increased at 4-12h, 2-4h, 8-24h, and 4-8h after irradiation in human peripheral blood irradiated at 0.5-10Gy in vitro, indicating significant dose and time dependence. The R2 of fitting curves were all higher than 0.9. Compared with the traditional lymphocyte counting, our method extended the time window of sample collection to $2-24 \mathrm{~h}$ after irradiation. This is of great significance in 
large-scale emergency rescue. The range of dose detection in our study was $0.5 \mathrm{~Gy}-10 \mathrm{~Gy}$, which is similar to the lymphocyte counting method. However, we could completely predict a higher dose according to the obtained curvilinear equation, within effective time range for detection. Furthermore, all the expression levels of four genes were stable in healthy population, and the difference was found between male and female. Apart from TRAF4, whose expression was slightly lower in the 30-40 age group, the other three genes could not be affected by age. Therefore, the accuracy of our model has more advantage than the traditional lymphocyte count analysis.

Chromosomal aberration analysis is considered as the gold standard for biological dose estimation due to its high accuracy and specificity (48). However, the detection process is relatively cumbersome, technically difficult, and requires professional laboratory. Moreover, Lymphocytes need to be cultured for 48 to 72 hours before analysis, which greatly lengthens time required. The conventional chromosome aberration analysis method is sufficient to dose estimation for a small number (from several to dozens of patients) of patients with acute external radiation, however it is essential to improve the throughput of analysis when deal with a large number of patients with external radiation. Lloyd DC suggested that slow analysis speed can be solved to a certain extent by reducing the initial number of cells to 50 or even 30 , when dealing with a large number of patients (49). However, the reduction of analyzed cells to 50 would cause an inaccuracy of $0.5 \sim 1.0 \mathrm{~Gy}$ in estimated dose, although the analysis speed is increased $(48,50)$. On the other hand, the manual operation is a main reason to limit the detection throughput. The automated harvesting and staining systems, as well as metaphase cell search systems and corresponding chromosome aberration analysis software have been developed to solve this problem, but the standard curve for dose estimation is established under the condition of manual specimen preparation and microscopic analysis. The efficiency of automatic analysis needs to be verified. In our study, four P53-related radiation-sensitive genes were effectively combined according to their specificity of expression level patterns, and the response time window and dose range of each gene covered and connected. This model can accurately estimate the dose for injured patients within $2 \mathrm{~h}-24 \mathrm{~h}$ after irradiation without cell culture process. Moreover, the rate of chromosome aberration was basically saturated at 5Gy, while the effective dose range of our model covered from 0.5Gy to 10Gy. In early of nuclear accident, our model can carry out high-throughput detection of samples without reducing the accuracy.

P53-related genes DDB2, AEN, TRIAP1 and TRAF4 with significant radio-sensitivity were screened from human peripheral blood irradiated, and this is the first time to investigate the potential biomarkers of ionizing radiation by systematic study. The expression levels of P53 signal-related genes such as DDB2, AEN, TRIAP1 and TRAF4 were significantly up-regulated by radiation, with time specificity and dose dependence in $2 \mathrm{~h}-24 \mathrm{~h}$ after irradiation. In addition, the expression levels of DDB2, AEN, TRIAP1 and TRAF4 in healthy population were stable and uniform, with no gender difference and less influenced by age, which could be used as indicators to identify person who has been exposed to radiation and need medical treatment. The effective combination of the four genes could achieve a more accurate dose assessment and injury classification for large-scale wounded patients within 24 hours post exposure, providing a basis for subsequent treatment plan formulation. 


\section{Conclusions}

Our study provides a new model for dose estimation and injury classification of a large number of exposed population in acute nuclear accidents, and also provides a new idea and method. With the development of radiation medicine, the range of time and dose detection of the model will be improved continuously, through continuous supplement or modification of novel radiation-sensitive genes according to the characteristics of different genes.

\section{Abbreviations}

DSB Double-strand break

DNA Deoxyribonucleic acid

ATM Ataxia telangiectasia mutation

RNA Ribonucleic Acid

cDNA complementary DNA

CT Cycle threshold

mRNA messengerRNA

PLS partial least-regression

FC Fold change

NER Nucleotide excision repair

\section{Declarations}

\section{Ethics approval and consent to participate}

All volunteers signed the informed consent to participate voluntarily on the premise of understanding the purpose and content of the research区Beijing Institute of Radiation Medicine Number: No.LLSC2016-014『

\section{Consent for publication}

Not applicable

\section{Availability of data and materials}

The datasets used and/or analyzed during the current study are available from the corresponding author on reasonable request. 


\section{Competing interests}

The authors declare that they have no competing interests.

\section{Funding}

This study was supported by the Major Project: BWS18J008 and Major Project AEP17J001

\section{Authors' contributions}

$P Z, Z W$ and $Y L$ contributed to the conception and design of the study. $W L, X L, L L$ and $Z Q$ contributed to the patient sample and data collection. WL囚SZ and MJ contributed to the acquisition, analysis, or interpretation of data. WL, SZ, YL and ZW drafted and revised the manuscript. All authors read and approved the final manuscript.

\section{Acknowledgements}

Not applicable.

\section{Author details}

1. Graduate Collaborative Training Base of Academy of Military Sciences, Hengyang Medical School, University of South China, Hengyang, Hunan, 421001

2. Department of Radiobiology, Beijing Key Laboratory for Radiobiology, Beijing Institute of Radiation Medicine, Beijing 100850, China

\section{References}

1. Voisin P, Barquinero F, Blakely B, Lindholm C, Lloyd D, Luccioni C, et al. Towards a standardization of biological dosimetry by cytogenetics. Cell Mol Biol (Noisy-le-grand). 2002;48(5):501-4.

2. Dainiak N, Waselenko JK, Armitage JO, MacVittie TJ, Farese AM. The hematologist and radiation casualties. Hematology Am Soc Hematol Educ Program. 2003:473-96.

3. Ponomarev AL, George K, Cucinotta FA. Computational model of chromosome aberration yield induced by high- and low-LET radiation exposures. Radiat Res. 2012;177(6):727-37.

4. Ropolo M, Balia C, Roggieri P, Lodi V, Nucci MC, Violante FS, et al. The micronucleus assay as a biological dosimeter in hospital workers exposed to low doses of ionizing radiation. Mutat Res. 2012;747(1):7-13.

5. Veremeyeva G, Akushevich I, Pochukhailova T, Blinova E, Varfolomeyeva T, Ploshchanskaya O, et al. Long-term cellular effects in humans chronically exposed to ionizing radiation. Health Phys. 2010;99(3):337-46.

6. Abe Y, Yoshida MA, Fujioka K, Kurosu Y, Ujiie R, Yanagi A, et al. Dose-response curves for analyzing of dicentric chromosomes and chromosome translocations following doses of 1000 mGy or less, based 
on irradiated peripheral blood samples from five healthy individuals. J Radiat Res. 2018;59(1):3542.

7. Benderitter M, Durand V, Caux C, Voisin P. Clearance of radiation-induced apoptotic lymphocytes: ex vivo studies and an in vitro co-culture model. Radiat Res. 2002;158(4):464-74.

8. Pandey BN, Kumar A, Ali M, Mishra KP. Bystander effect of conditioned medium from low and high doses of gamma-irradiated human leukemic cells on normal lymphocytes and cancer cells. J Environ Pathol Toxicol Oncol. 2011;30(4):333-40.

9. Andrievski A, Wilkins RC. The response of gamma-H2AX in human lymphocytes and lymphocytes subsets measured in whole blood cultures. Int J Radiat Biol. 2009;85(4):369-76.

10. Wang Z, Hu H, Hu M, Zhang X, Wang Q, Qiao Y, et al. Ratio of gamma-H2AX level in lymphocytes to that in granulocytes detected using flow cytometry as a potential biodosimeter for radiation exposure. Radiat Environ Biophys. 2014;53(2):283-90.

11. Schuch AP, Garcia CC, Makita K, Menck CF. DNA damage as a biological sensor for environmental sunlight. Photochem Photobiol Sci. 2013;12(8):1259-72.

12. Deycmar S, Faccin E, Kazimova T, Knobel PA, Telarovic I, Tschanz F, et al. The relative biological effectiveness of proton irradiation in dependence of DNA damage repair. $\mathrm{Br} \mathrm{J}$ Radiol. 2020;93(1107):20190494.

13. Nikitaki Z, Mavragani IV, Laskaratou DA, Gika V, Moskvin VP, Theofilatos K, et al. Systemic mechanisms and effects of ionizing radiation: A new 'old' paradigm of how the bystanders and distant can become the players. Semin Cancer Biol. 2016;37-38:77-95.

14. Santivasi WL, Xia F. Ionizing radiation-induced DNA damage, response, and repair. Antioxid Redox Signal. 2014;21(2):251-9.

15. Sanders JT, Freeman TF, Xu Y, Golloshi R, Stallard MA, Hill AM, et al. Radiation-induced DNA damage and repair effects on 3D genome organization. Nat Commun. 2020;11(1):6178.

16. Ditch S, Paull TT. The ATM protein kinase and cellular redox signaling: beyond the DNA damage response. Trends Biochem Sci. 2012;37(1):15-22.

17. Ragunathan K, Upfold NLE, Oksenych V. Interaction between Fibroblasts and Immune Cells Following DNA Damage Induced by lonizing Radiation. Int J Mol Sci. 2020;21(22).

18. Bauer M, Goldstein M, Christmann M, Becker H, Heylmann D, Kaina B. Human monocytes are severely impaired in base and DNA double-strand break repair that renders them vulnerable to oxidative stress. Proc Natl Acad Sci U S A. 2011;108(52):21105-10.

19. Sun X, Liu M, Bai J, Xu J, Zhu C, Dong J, et al. ATR kinase activity promotes antibody class switch recombination in $B$ cells through cell cycle regulation without suppressing DSB resection and microhomology usage. J Leukoc Biol. 2021.

20. Zhao K, Wang X, Xue X, Li L, Hu Y. A long noncoding RNA sensitizes genotoxic treatment by attenuating ATM activation and homologous recombination repair in cancers. PLoS Biol. 2020;18(3):e3000666. 
21. Matsuoka S, Rotman G, Ogawa A, Shiloh Y, Tamai K, Elledge SJ. Ataxia telangiectasia-mutated phosphorylates Chk2 in vivo and in vitro. Proc Natl Acad Sci U S A. 2000;97(19):10389-94.

22. Vousden KH, Prives C. Blinded by the Light: The Growing Complexity of p53. Cell. 2009;137(3):41331.

23. Zhidong W, Liping S, Zhongwu L, Xueqing Z, Xiaoxin L, Ying C. Screening of biomarker for radiation injury using microassay. Journal of Radiation Research and Radiation Processing.2014; 32(5):3541.

24. Sugaya M, Funamizu K, Kono M, Okuno Y, Kondo T, Ono R, et al. Whole-exome sequencing and host cell reactivation assay lead to a diagnosis of xeroderma pigmentosum group $\mathrm{D}$ with mild ultraviolet radiation sensitivity. J Dermatol. 2021;48(1):96-100.

25. Lacombe J, Sima C, Amundson SA, Zenhausern F. Candidate gene biodosimetry markers of exposure to external ionizing radiation in human blood: A systematic review. PLoS One. 2018;13(6):e0198851.

26. Li S, Lu X, Feng JB, Tian M, Wang J, Chen H, et al. Developing Gender-Specific Gene Expression Biodosimetry Using a Panel of Radiation-Responsive Genes for Determining Radiation Dose in Human Peripheral Blood. Radiat Res. 2019;192(4):399-409.

27. Tavakoli H, Manoochehri M, Modarres Mosalla SM, Ghafori M, Karimi AA. Dose-dependent and gender-related radiation-induced transcription alterations of Gadd45a and ler5 inhuman lymphocytes exposed to gamma ray emitted by (60)Co. Radiat Prot Dosimetry. 2013;154(1):37-44.

28. Tilton SC, Markillie LM, Hays S, Taylor RC, Stenoien DL. Identification of Differential Gene Expression Patterns after Acute Exposure to High and Low Doses of Low-LET lonizing Radiation in a Reconstituted Human Skin Tissue. Radiat Res. 2016;186(5):531-8.

29. Visweswaran S, Joseph S, Dhanasekaran J, Paneerselvam S, Annalakshmi O, Jose MT, et al. Exposure of patients to low doses of X-radiation during neuro-interventional imaging and procedures: Dose estimation and analysis of gamma- $\mathrm{H} 2 \mathrm{AX}$ foci and gene expression in blood lymphocytes. Mutat Res. 2020;856-857:503237.

30. Han C, Zhao R, Kroger J, He J, Wani G, Wang QE, et al. UV radiation-induced SUMOylation of DDB2 regulates nucleotide excision repair. Carcinogenesis. 2017;38(10):976-85.

31. Visweswaran S, Joseph S, S VH, O A, Jose MT, Perumal V. DNA damage and gene expression changes in patients exposed to low-dose $X$-radiation during neuro-interventional radiology procedures. Mutat Res. 2019;844:54-61.

32. Stoyanova T, Roy N, Kopanja D, Raychaudhuri P, Bagchi S. DDB2 (damaged-DNA binding protein 2) in nucleotide excision repair and DNA damage response. Cell Cycle. 2009;8(24):4067-71.

33. Zou N, Xie G, Cui T, Srivastava AK, Qu M, Yang L, et al. DDB2 increases radioresistance of NSCLC cells by enhancing DNA damage responses. Tumour Biol. 2016;37(10):14183-91.

34. Kannan K, Amariglio N, Rechavi G, Jakob-Hirsch J, Kela I, Kaminski N, et al. DNA microarrays identification of primary and secondary target genes regulated by $\mathrm{p} 53$. Oncogene. 2001;20(18):2225-34. 
35. Drigeard Desgarnier MC, Rochette PJ. Enhancement of UVB-induced DNA damage repair after a chronic low-dose UVB pre-stimulation. DNA Repair (Amst). 2018;63:56-62.

36. Andrysik Z, Kim J, Tan AC, Espinosa JM. A genetic screen identifies TCF3/E2A and TRIAP1 as pathway-specific regulators of the cellular response to p53 activation. Cell Rep. 2013;3(5):1346-54.

37. Potting C, Tatsuta T, Konig T, Haag M, Wai T, Aaltonen MJ, et al. TRIAP1/PRELI complexes prevent apoptosis by mediating intramitochondrial transport of phosphatidic acid. Cell Metab. 2013;18(2):287-95.

38. Frigerio M, Passeri E, de Filippis T, Rusconi $D$, Valaperta $R$, Carminati $M$, et al. SNPs and real-time quantitative PCR method for constitutional allelic copy number determination, the VPREB1 marker case. BMC Med Genet. 2011;12:61.

39. He L, Chinnery PF, Durham SE, Blakely EL, Wardell TM, Borthwick GM, et al. Detection and quantification of mitochondrial DNA deletions in individual cells by real-time PCR. Nucleic Acids Res. 2002;30(14):e68.

40. Camilleri-Broet S, Cremer I, Marmey B, Comperat E, Viguie F, Audouin J, et al. TRAF4 overexpression is a common characteristic of human carcinomas. Oncogene. 2007;26(1):142-7.

41. Li W, Peng C, Lee MH, Lim D, Zhu F, Fu Y, et al. TRAF4 is a critical molecule for Akt activation in lung cancer. Cancer Res. 2013;73(23):6938-50.

42. Gu X, Coates PJ, MacCallum SF, Boldrup L, Sjostrom B, Nylander K. TRAF4 is potently induced by TAp63 isoforms and localised according to differentiation in SCCHN. Cancer Biol Ther. 2007;6(12):1986-90.

43. Mandriani B, Castellana S, Rinaldi C, Manzoni M, Venuto S, Rodriguez-Aznar E, et al. Identification of p53-target genes in Danio rerio. Sci Rep. 2016;6:32474.

44. Sax JK, El-Deiry WS. Identification and characterization of the cytoplasmic protein TRAF4 as a p53regulated proapoptotic gene. J Biol Chem. 2003;278(38):36435-44.

45. Shi C, Rao C, Sun C, Yu L, Zhou X, Hua D, et al. miR-29s function as tumor suppressors in gliomas by targeting TRAF4 and predict patient prognosis. Cell Death Dis. 2018;9(11):1078.

46. Shen W, Zhang Z, Ma J, Lu D, Lyu L. The Ubiquitin Proteasome System and Skin Fibrosis. Mol Diagn Ther. 2021;25(1):29-40.

47. Azizova TV, Osovets SV, Day RD, Druzhinina MB, Sumina MV, Pesternikova VS, et al. Predictability of acute radiation injury severity. Health Phys. 2008;94(3):255-63.

48. Sproull MT, Camphausen KA, Koblentz GD. Biodosimetry: A Future Tool for Medical Management of Radiological Emergencies. Health Secur. 2017;15(6):599-610.

49. Lloyd DC, Edwards AA, Moquet JE, Guerrero-Carbajal YC. The role of cytogenetics in early triage of radiation casualties. Appl Radiat Isot. 2000;52(5):1107-12.

50. Voisin P, Benderitter M, Claraz M, Chambrette V, Sorokine-Durm I, Delbos M, et al. The cytogenetic dosimetry of recent accidental overexposure. Cell Mol Biol (Noisy-le-grand). 2001;47(3):557-64. 


\section{Figures}

a
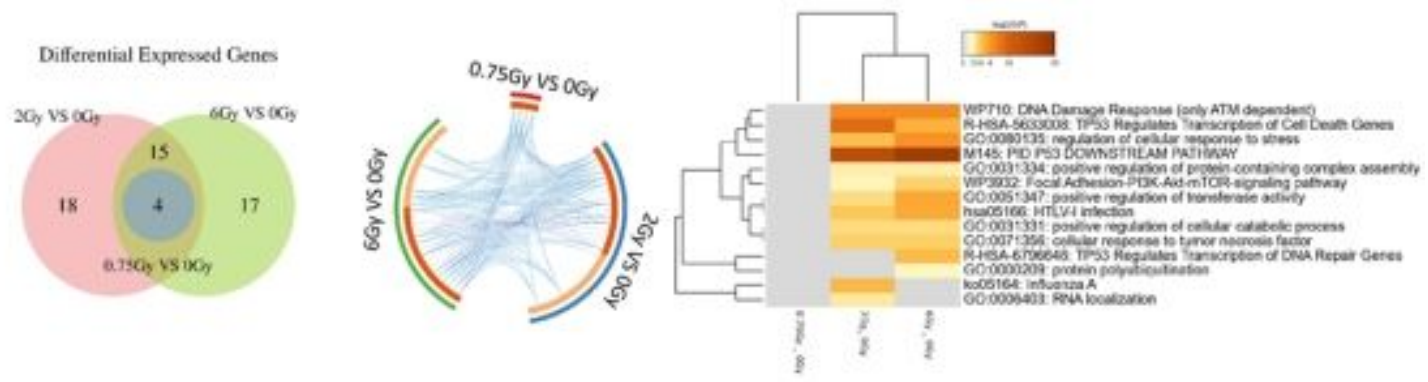

b

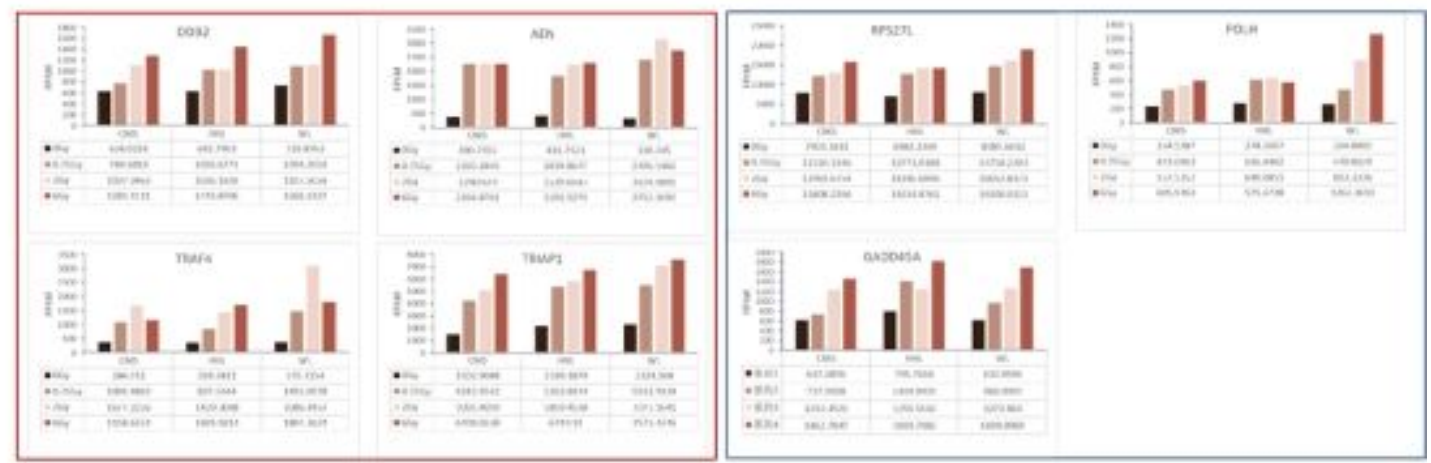

\section{Figure 1}

Analyses of differentially expressed genes in human peripheral blood 2 hours after $\gamma$-ray irradiated. (a) Overlap analysis was performed on differentially expressed genes in $2 \mathrm{~h}$ after different doses of irradiation. Functional annotation analysis were performed on these differentially expressed genes, On the outside, each arc represents the identity of each gene list, each deep orange arc inside the diagram represents a gene that appears in multiple lists and the light orange arc represents a single gene in that list, the purple line connects differentially expressed genes that were common to the different dose groups and the blue line connects differentially expressed genes enriched in the same GO term. All statistically enriched were hierarchically clustered into a tree and 0.3 kappa score was applied as the threshold to cast the tree into term clusters; the heatmap cells are colored by their p-values, white cells indicate the lack of enrichment for that term in the corresponding gene list. (b) Expression levels of P53 related candidate genes in human peripheral blood before and after different doses of irradiation. 
a

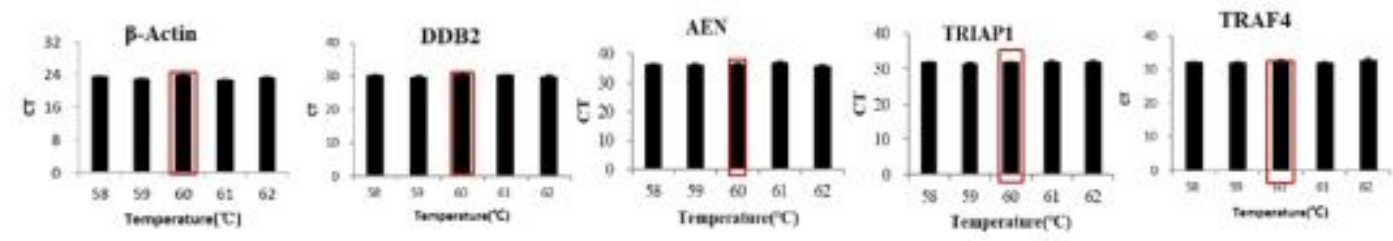

b
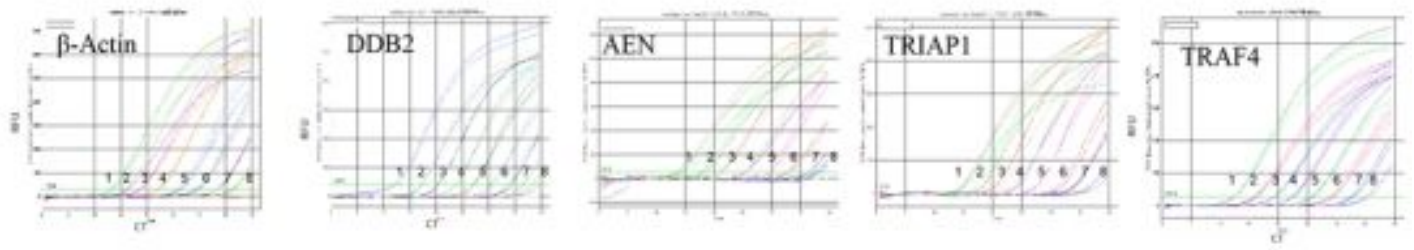

c
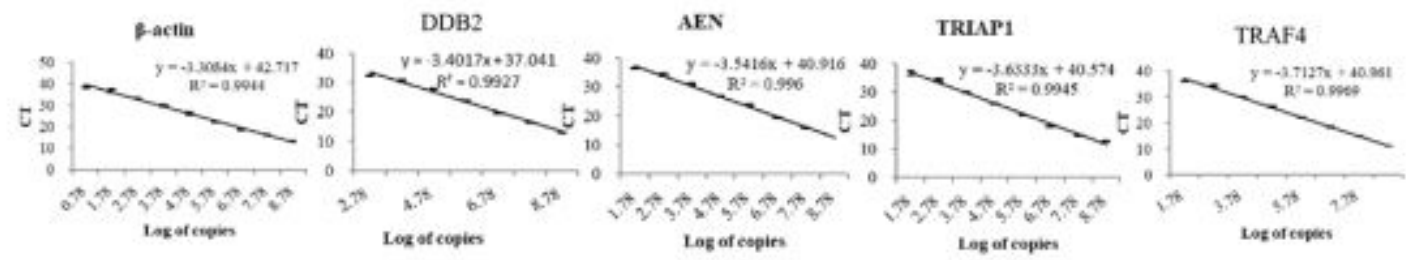

\section{Figure 2}

Real-time fluorescence quantitative PCR detection methods Established for target genes. (a)The CT

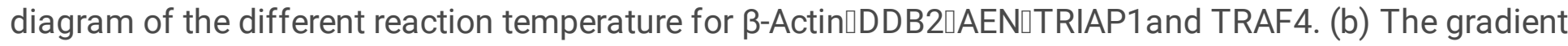

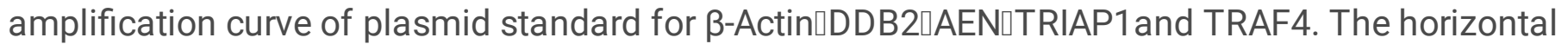
coordinate of CT is cycle numbers, the vertical coordinate of RFU is fluorescence intensity. Plasmid concentration of $1-8$ is $6 \times 108,6 \times 107,6 \times 106,6 \times 105,6 \times 104,6 \times 103,6 \times 102$ and negative. (c) Standard curves of 5 genes were plotted using the copy number de-log of plasmid standard as the $x$-coordinate and the $\mathrm{Ct}$ value as the $\mathrm{y}$-coordinate 
a
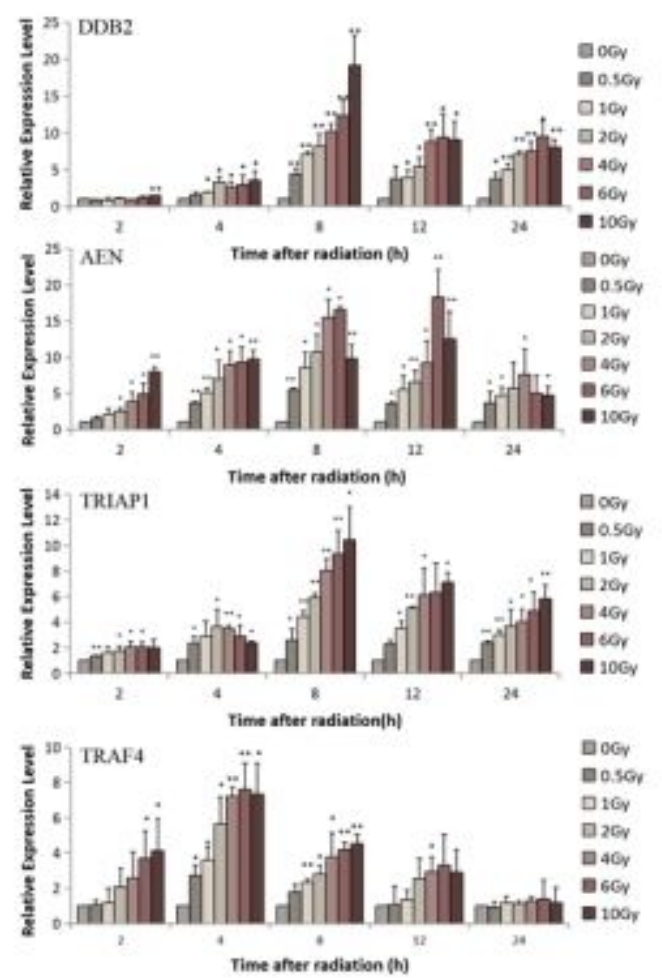

b

\begin{tabular}{c|c|ccc|c|}
\hline DDB2 & 2h & $4 h$ & $8 h$ & $12 h$ & $24 h$ \\
\hline $0 G y$ & 1 & 1 & 1 & 1 & 1 \\
\hline $0.5 G y$ & 0.91 & 1.54 & 4.39 & 3.75 & 3.71 \\
$1 G y$ & 0.60 & 1.89 & 7.11 & 3.86 & 4.98 \\
2 Gy & 1.15 & 2.13 & 8.16 & 5.37 & 7.10 \\
$4 G y$ & 0.68 & 2.59 & 10.19 & 8.79 & 7.48 \\
6 Gy & 1.18 & 2.97 & 12.36 & 9.37 & 9.45 \\
$10 G y$ & 1.44 & 3.58 & 19.17 & 9.09 & 7.99 \\
\hline
\end{tabular}

\begin{tabular}{|c|c|c|c|c|c|}
\hline AEN & $2 \mathrm{~h}$ & th & $8 \mathrm{~h}$ & $12 \mathrm{~h}$ & $24 \mathrm{~h}$ \\
\hline $0 Q y$ & 1 & 1 & 1 & 1 & 1 \\
\hline $0.56 y$ & 152 & 3.66 & 5.47 & 3.58 & 3.70 \\
\hline $10 y$ & 205 & 5.10 & 8.45 & 5.51 & 4.68 \\
\hline $20 y$ & 253 & 701 & 10.66 & 6.52 & 5.67 \\
\hline $4 G y$ & 387 & 8.90 & 15.53 & 9.17 & 7.59 \\
\hline $6 G y$ & 4.86 & 929 & 16.57 & 18.33 & 4.95 \\
\hline $10 G y$ & 7.97 & 9.75 & 9.78 & 12.49 & 4.69 \\
\hline
\end{tabular}

\begin{tabular}{c|c|c|ccc|}
\hline TRIAP1 & 2h & $4 h$ & gh & $12 \mathrm{~h}$ & $24 \mathrm{~h}$ \\
\hline OGy & 1 & 1 & 1 & 1 & 1 \\
\hline $0.5 \mathrm{~Gy}$ & 1.34 & 2.35 & 2.59 & 2.29 & 2.37 \\
$1 \mathrm{~Gy}$ & 1.62 & 2.89 & 4.43 & 3.51 & 2.99 \\
$2 \mathrm{~Gy}$ & 1.74 & 3.65 & 5.92 & 5.12 & 3.69 \\
$4 \mathrm{~Gy}$ & 2.03 & 3.47 & 8.06 & 6.10 & 4.04 \\
$6 \mathrm{~Gy}$ & 2.02 & 2.88 & 9.35 & 6.32 & 4.85 \\
$10 \mathrm{~Gy}$ & 2.00 & 2.37 & 10.44 & 7.13 & 5.83 \\
\hline
\end{tabular}

\begin{tabular}{|c|c|c|c|c|c|}
\hline TRAF4 & $2 \mathrm{~h}$ & $4 h$ & gh & $12 \mathrm{~h}$ & $24 h$ \\
\hline $0 G y$ & 1 & 1 & 1 & 1 & 1 \\
\hline $0.56 y$ & 1.04 & 2.73 & 1.77 & 1.05 & 0.99 \\
\hline $19 y$ & 1.16 & 3.58 & 2.33 & 1.37 & 1.17 \\
\hline $20 y$ & 2.07 & 5.63 & 2.78 & 2.54 & 1.12 \\
\hline $4 G y$ & 3.42 & 7.20 & 3.76 & 2.94 & 1.29 \\
\hline $60 y$ & 3.67 & 7.61 & 4.19 & 3.31 & 1.39 \\
\hline $106 y$ & 4.12 & 7.33 & 4.51 & 2.89 & 1.18 \\
\hline
\end{tabular}

Figure 3

Analysis of time and dose effects of radiation-sensitive genes. (a) The histogram shows the time effect

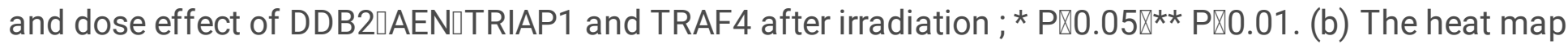
shows the response time window and change pattern of DDB2 $₫ A E N \square T R I A P 1$ and TRAF4 after exposure to ionizing radiation. Cells are colored by their fold change, black windows frame the time range of the genes response to radiation dose.

a

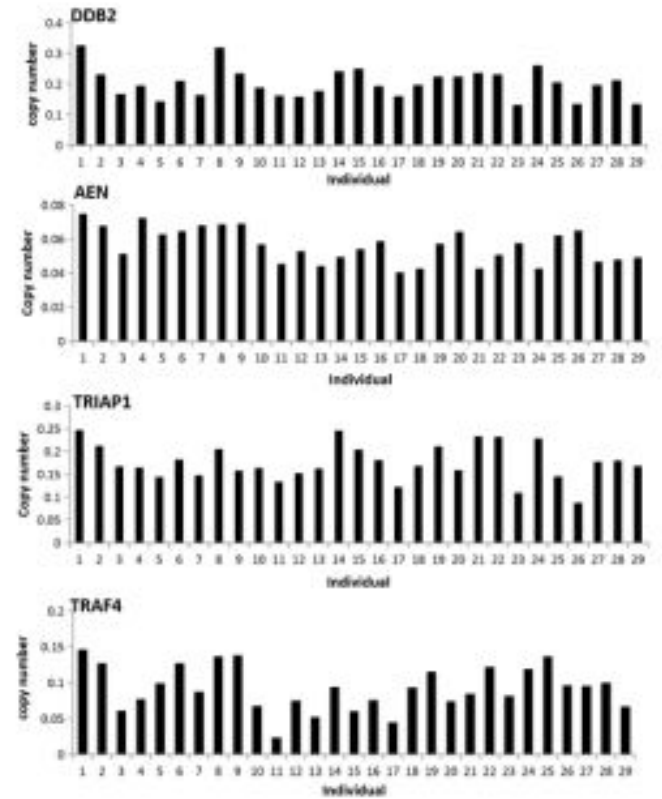

b
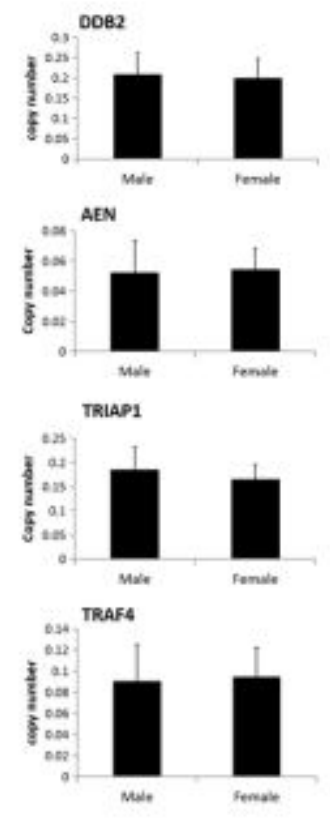
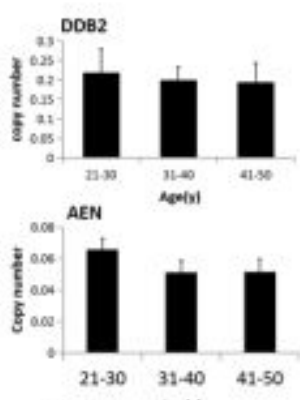

TrLap1 Aemin
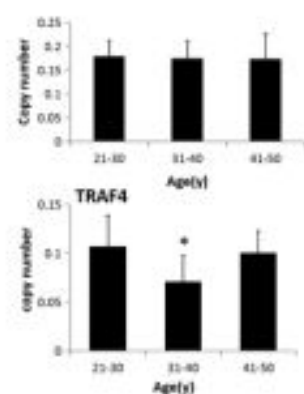

Figure 4 
Baseline level analysis of DDB2, AEN, TRIAP1 and TRAF4 in healthy population. (a) Collected the venous blood from 29 healthy volunteers (age ranging from 20 to 50 years old, male: 15 and female: 14), and analyze the expression levels of DDB2, AEN, TRIAP1, and TRAF4. (b)The effects of gender and age on DDB2, AEN, TRIAP1 and TRAF4 gene expression were analyzed (* P囚0.05).

a

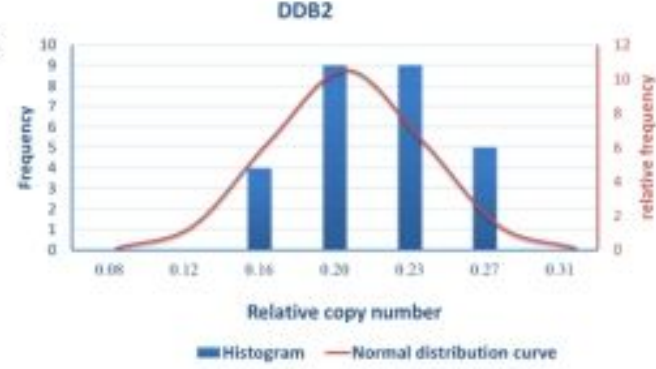

TRIAP1

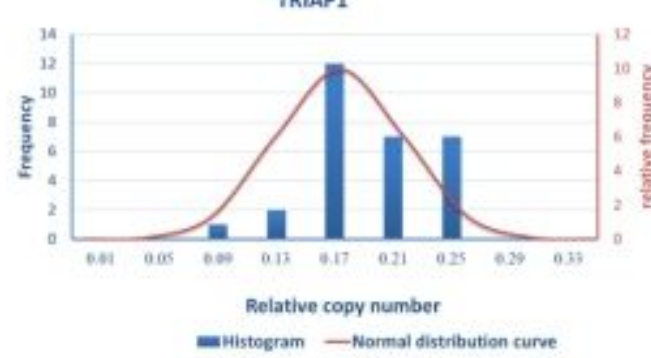

AEN

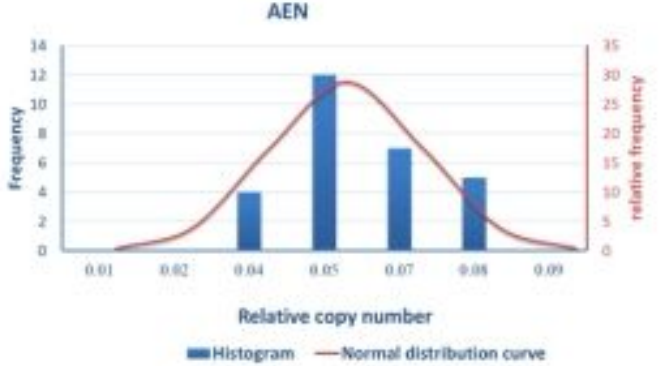

- Histogram -Normal distribution curve

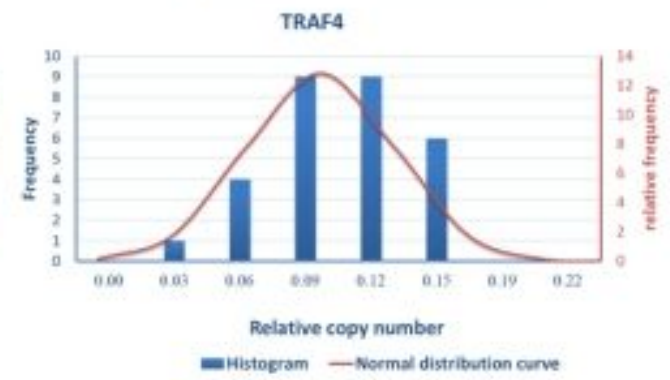

b Radiation TrAFa

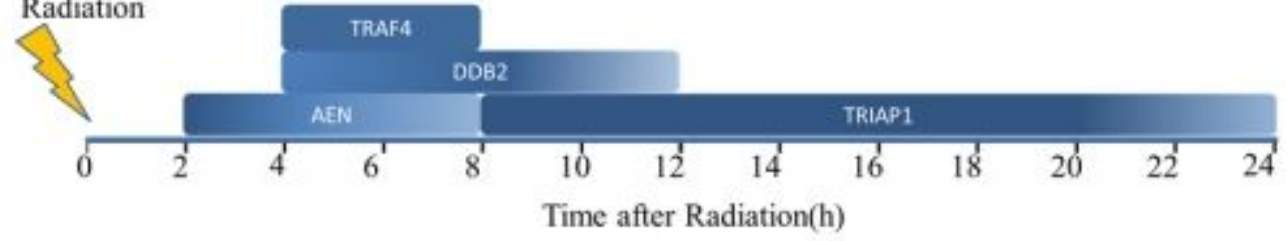

\begin{tabular}{|c|c|c|c|c|c|}
\hline & $2 \mathrm{~h}$ & $4 \mathrm{~h}$ & 8h & $12 \mathrm{~h}$ & $24 h$ \\
\hline AEN & $\begin{array}{l}\text { Dose }=1.5129-\mathrm{AEN}-1.8314 \\
g^{2}=0.9140(0.5-100 y)\end{array}$ & 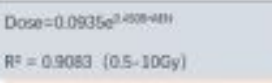 & 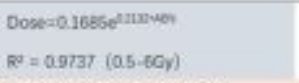 & & \\
\hline DOB2 & & $\begin{array}{l}D 05 e=46682 \cdot D D E 2 \cdot 7.4239 \\
R^{2}=0.9697 \quad(0.5-100 \mathrm{y})\end{array}$ & $\begin{array}{l}\text { Dose }=0.6926 \cdot 0082-31694 \\
\mathrm{RN}^{\mathrm{N}}=0.9755(0.5-100 \mathrm{y})\end{array}$ & $\begin{array}{l}\text { Dose }=0.2064 e^{0 \text { now }} \\
R^{t}=0.9542\{0.5-60 \mathrm{y}\}\end{array}$ & \\
\hline \multirow[t]{2}{*}{ TRIAP1 } & & & Dowe-0.1956 entaravi & Dese-01147 eneserews & $\begin{array}{l}\text { Dose } 0.5452 \cdot \text { TRIAP12 }^{2} \\
\text { 16606*TRLAPI+12567 }\end{array}$ \\
\hline & & & Eo - a.pos $\langle 0.5-100 y)$ & $R^{\prime}=0.9743(05-1009)$ & 50 - $0.5 a 90(0.5-100 y)$ \\
\hline TRAF4 & & 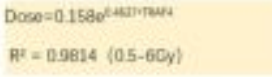 & 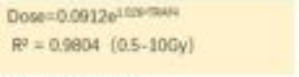 & & \\
\hline \multirow{2}{*}{ Model } & DOSE-1.5129-AEN - 18314 & Dose $=0.374 \cdot T R A 4 A^{\prime}+0.541 \cdot C D E Z$ & $\begin{array}{l}\text { Done-0.111-AEN- } \\
\text { O.109-TRAAP1 + 0.941-DCEZ + 0.006- T } \\
\text { RAS4 }\end{array}$ & 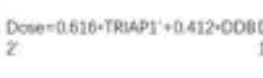 & $\begin{array}{l}\text { Dose-0.5452*TRIAP17 } \\
1.6696+\text { TRIAP1+12567 }\end{array}$ \\
\hline & $B^{2}=0.9346$ & $A^{0}=0.0 .23$ & $R^{0}=0.831$ & $\mathrm{~A}^{2}=0 \mathrm{~B} 67$ & $R^{d}=0.9996$ \\
\hline
\end{tabular}

\section{Figure 5}

Gene expression distribution curve in population and radiation dose assessment model of combined genes. (a) The total normal distribution curves of DDB2, AEN, TRIAP1 and TRAF4 expressed in population. (b) Model of DDB2, AEN, TRIAP1 and TRAF4 response time to ionizing radiation. (c)The single gene dose estimation equation was fitted at each time point In the dose range with significant dose dependence, and the final dose estimation equation was fitted accordingly.

\section{Supplementary Files}


This is a list of supplementary files associated with this preprint. Click to download.

- supplementarytable1.xlsx

- supplementarytable2.xlsx

- supplementarytable3.xlsx 